\title{
Acceptability of depot medroxyprogesterone in women attending general outpatient department: A cross sectional study
}

\author{
S Chaudhuri, B.K.Rai , R Giri, A Yadav,S Giri \\ Department of General Practice and Emergency Medicine \\ B.P.Koirala Institute of Health Sciences, Dharan, Nepal
}

\begin{abstract}
Background: Depomedroxy progesterone (DMPA) is most commonly used contraception among the Nepalese women of reproductive age group. Objective: To study the perceived positive and negative aspects regarding the use of DMPA amongst women presenting to the General Outpatient Department of BPKIHS, Dharan, Nepal. Method: This is a cross sectional descriptive study which is conducted at the general out patient department (GOPD) of the B.P. Koirala Institite of Health Science, Dharan, Nepal for a period of one year where a questionnaire was distributed among 100 female patients and their responses were collected. Result: Most widely used contraceptive method was Depot Medroxy progesterone (69\%). The most sought after reason for continued use, was "easy to follow dose" (30\%) whereas "difficulty with compliance with other contraception" (26\%) remains the next important reason. "Privacy (16\%) helped the patients to continue the usage whereas "Easily/only available contraception (5\%) made rest of the participants to continue the use of Depot medroxyprogesterone. Conclusion: Depot Medroxy Progesterone Acetate is a highly effective, convenient to use non daily hormonal contraception which is widely accepted in Nepalese women when used after proper counselling by clinicians or other health professionals.
\end{abstract}

Key words: Acceptability, Contraception, Depo medroxy progesterone.

\section{Introduction}

Depo-Provera (depot medroxyprogesterone acetate, or DMPA) is a long-acting, progesterone-only, injectable contraceptive

\footnotetext{
Address for correspondence

Dr. Sonai Chaudhuri

Assistant Professor

Department of GP \& EM

B.P. Koirala Institute of Health Sciences, Dharan

E-mail: sonaichaudhuri10@gmail.com

Phone no: 977-9847045136
}

currently used by many women to overcome the inconvenience of daily compliance of contraception. ${ }^{1,2 .}$

Depo-Provera is currently formulated as an aqueous microcrystalline suspension of a synthetic progestin which is administered by deep intramuscular injection at a dose of 150 mg every 12 weeks. Pharmacologically 
active levels are achieved within 24 hours after injection, and serum concentrations of 1 $\mathrm{ng} / \mathrm{mL}$ are maintained for three months. During the fifth or sixth month after injection, the levels decrease to $0.2 \mathrm{ng} / \mathrm{mL}$, and they become undetectable by 7-9 months after injection. ${ }^{1,2,3,4}$

DMPA acts by the inhibition of ovulation with the suppression of follicle-stimulating hormone (FSH) and LH levels and eliminates the $\mathrm{LH}$ surge resulting in a hypoestrogenic state. $^{5}$

DMPA being every three monthly method ,reflects the pregnancy rate being low not only with "perfect use," but also with typical use .It also has a lower rate of first-year failure associated with typical use (0.3$3.0 \%$. 6.7 It is an extremely effective contraceptive option with a failure rate of $0.3 \%$. ${ }^{3}$ It may improve conditions such as menorrhagia, dysmenorrhea and iron deficiency anemia and may be of particular benefit for women with menstrual cyclerelated disorders, such as premenstrual syndrome or migraine headaches. ${ }^{4}$

It is regarded safe for breastfeeding mothers. ${ }^{3}$ Approximately $70 \%$ of former users desiring pregnancy conceive within 12 months, and $90 \%$ of former users conceive within 24 months. $^{8}$

Disruption of the menstrual cycle to eventual amenorrhea occurs in approximately $70 \%$ of Depot Medroxy Progesterone Acetate users by 12 months of use.,10. Irregular menstruation lasts as long as 1 year after the last injection. Other menstrual changes, such as spotting/irregular bleeding (46\%) and longer durations of menses (26\%), were relatively common in the initial three months, these decreased over time to $39.5 \%$ and $18.5 \%$, respectively, at nine months. ${ }^{10}$ Although the irregular bleeding with its use declines significantly with time and amenorrhea usually ensues, becoming the major reason for patient discontinuation. ${ }^{7}$ The need for only four injections per year makes it an appropriate option for women who desire convenience and privacy, as well as for those patients who have problems complying with self-administered or daily methods. The return of fertility is delayed but will conceive within 10months after last injection. ${ }^{7,11}$

Doctors can hence greatly reduce patient anxiety and increase contraceptive success to therapy through appropriate counselling of the compliant patient to manage the concerns among DMPA users.

\section{Methods}

This cross sectional descriptive study was conducted at the general out patient department (GOPD) of the B.P. Koirala Institite of Health Sciences, Dharan, Nepal from September 2008 to February 2009 with a sample size of 100 done by convinient sampling. Sample were females of a Age 
group of 18 to 45 years, married,willing to participate in the study. Samples were excluded who were not willing to participate.

A self administered questionnaire was distributed to all the females fulfilling the inclusion criteria attending the GOPD on the researchers GOPD duty days. The questionnaire reviewed the preferred method of contraception available to them and were asked about their present use of DMPA. If they had previously used but stopped, then their reasons for discontinuation were questioned. If they had never used, reasons were sought for their consideration for using DMPA.

The completed questionnaire is then reviewed during interview by the researcher with each patient to clarify validity and accuracy of the answers. The results were entered into excel database and reported in percentage terms, stratified according to the questions and responses of the participants.

The data were analyzed using SPSS 12.0

\section{Results}

Most widely used contraceptive method was DepotMedroxy progesterone was used continuously (69\%). The most sought after reason by users was easy to follow dose $(30 \%)$ whereas difficulty with compliance with other contraception (26\%) remains the next important reason. Privacy (16\%) helped the patients to continue the usage whereas easily/only available contraception (5\%) made rest of the participants to continue the use of depot medroxyprogesterone. Participants who preferred not to use it as their contraceptive method were $12 \%$ whereas $19 \%$ discontinued. The most important reasons for stopping were irregular bleeding (12\%) and weight gain (8\%), fear of weight gain $(4 \%)$ and preference to have menstruation every month (3\%). Twelve percent of the women did not use Depot medroxyprogesterone as their contraceptive method. software programme.

\begin{tabular}{|l|l|c|}
\hline \multicolumn{1}{|c|}{ Variables } & \multicolumn{1}{|c|}{ Categories } & No. of patient \\
\hline Q1.What methods of contraception are & OCP & 14 \\
\cline { 2 - 3 } you currently using? & Condoms & 7 \\
\cline { 2 - 3 } & IUD & 2 \\
\cline { 2 - 3 } & Diaphragm/Cap & 1 \\
\cline { 2 - 3 } & Natural method & 75 \\
\cline { 2 - 3 } & Depot & 19 \\
\hline Q2. Have you ever used 3 monthly depot & Yes \& stopped & 1 \\
\hline
\end{tabular}




\begin{tabular}{|c|c|c|}
\hline \multirow[t]{2}{*}{ injections? } & No & 12 \\
\hline & Yes \& continuing & 69 \\
\hline \multirow[t]{6}{*}{$\begin{array}{l}\text { Q3.What was/were your reason/s for } \\
\text { stopping it? }\end{array}$} & $\begin{array}{l}\text { Having to visit doctor/clinic } \\
\text { every } 3 \text { months. }\end{array}$ & 3 \\
\hline & Weight gain & 8 \\
\hline & Headaches & 3 \\
\hline & $\begin{array}{l}\text { Wishing to return to fertility/ } \\
\text { get pregnant }\end{array}$ & 2 \\
\hline & Irregular bleeding & 12 \\
\hline & Absent periods & 6 \\
\hline \multirow{2}{*}{$\begin{array}{l}\text { Q4.Have you ever considered using depot } \\
\text { as a contraceptive method? }\end{array}$} & Yes & 4 \\
\hline & No & 8 \\
\hline \multirow{6}{*}{$\begin{array}{l}\text { Q5. What was/ were/ are your reason/s for } \\
\text { not using it? }\end{array}$} & Fear of needles/injections & 2 \\
\hline & Fear of weight gain. & 4 \\
\hline & $\begin{array}{l}\text { Prefer to have period every } \\
\text { month }\end{array}$ & 3 \\
\hline & Delay to return to fertility & 1 \\
\hline & $\begin{array}{l}\text { Not being able to stop the } \\
\text { contraception straight away. }\end{array}$ & 1 \\
\hline & $\begin{array}{l}\text { Have good knowledge about } \\
\text { natural method. }\end{array}$ & 1 \\
\hline \multirow{4}{*}{$\begin{array}{l}\text { Q6. Why did/do you considered } \\
\text { using/use/still using Depot as your } \\
\text { contraception method? }\end{array}$} & Privacy. & 16 \\
\hline & $\begin{array}{l}\text { Difficulty with compliance of } \\
\text { other contraceptives. }\end{array}$ & 26 \\
\hline & Easy to follow the dose. & 30 \\
\hline & $\begin{array}{l}\text { Easily/only available } \\
\text { contraception in the area. }\end{array}$ & 5 \\
\hline
\end{tabular}

\section{Discussion}

Depot medroxyprogesterone acetate (DMPA) injection is an excellent method of contraception for women who desire a long- term, reversible contraceptive method. It is highly effective, private, and avoids the need for daily compliance or near the time of sexual intercourse. ${ }^{2}$ The first dose of DMPA is 
given during the first seven days of the menstrual period, it prevents pregnancy immediately. ${ }^{3}$

This observational study directed on the views and attitude of the women attending the BPKIHS General Outpatient department, who were mostly the users of this contraceptive method.

Women who are on regular contraception preferred depot medroxyprogesterone. The reason being the easiest to follow the contraceptive regimen and difficulty in compliance with other methods like Oral contraceptive pills which had regular usage and chances of compliance is low. ${ }^{4}$

The draw backs which was mostly seen in the non users and in whom the preferred method was not Depot medroxy progesterone were Irregular bleeding which contributed to major factor for non compliance. According to a prospective study by Cromer et al $25 \%$ of the first time users stopped using in the first year because of dissatisfaction with bleeding patterns $^{10,12}$. Structured counseling prior to Depot Medroxy Progesterone Acetate use increases continuation rates at one year of use, and decreases discontinuation due to bleeding. With continued use of depot medroxy progesterone acetate, revealed the most common bleeding pattern is, no bleeding or absence of all bleeding including spotting. ${ }^{12}$ This detailed evaluation of the outcome of this research could not be achieved as limited duration of this study.

The second most important issue for discontinuation of use of depot medroxy progesterone was weight gain $(8 \%)$ in this observational study. According to a study done by Berenson et.al, DMPA users increased their weight $(+5.1 \mathrm{~kg})$, body fat $(+4.1 \mathrm{~kg})$, percent body fat (+3.4 percent) and central to peripheral fat $(+0.1)$ significantly more than users of oral contraception and nonhormonal contraception ${ }^{13}$. In this study population, the accurate increased weight gain was not calculated and only observational reporting was done. Informed users of depo medroxy progesterone are much more likely to become highly satisfied users with high continuation rates. Therefore, thorough, candid counselling about side effects is very important.

New acceptor of the spacing methods preferred Depot Medroxy progesterone from the numbers of past users (240285 in year 2069/070) to an increase number of users (235551 in year 2070/071). This is due to the availability of the contraceptive method in all Primary health centres and health institution in the country in different development regions of Nepal. ${ }^{14}$

Good patient education by the clinicians about the adverse effects of this method have proven the results of this improvement in the compliance. Hence the variability of adverse 
effects can be managed at any level of the Health system of Nepal.

\section{Limitation of study}

Although all the beneficial and non beneficial effects of Depot medroxy progesterone had variable patient response but the acceptability remains high. The limitations were mostly due to lack of time and small sample size. Time duration of the interview was limited as more time would enable to explore the views which were not retrieved adequately. The small study group was either from the extremes of the social geography which had high incidence variability and did not perfectly match with the whole population of the eastern developmental region of Nepal with poor health facility. But with further development in the health sector, Government of Nepal is adequately providing the required knowledge, attitude and practical methods to improve the acceptability of contraceptive methods.

\section{References}

1. J. Jain, A. J. Jakmiuk, F. R. Bode, D. Ross, A. M. Kaunitz. Contraceptive efficacy \& safety of DMPA-SC. Contraception 2004;269-275

2. F. Lakha, C.Henderson, A. Glasier. The acceptability of self administration of scdepo-provera. Contraception 2004; 14-18.

3. C. Westhoff. DMPA: A highly effective contraceptive option with proven long term safety. Contraception 2003:75-87.

4. P. J. Hillard. Oral contraception non compliance: extent of problem. Advanced contraception 1992;8 :13-20.

5. Guyton \& Hall. Textbook of physiology $9^{\text {th }}$ edition:1022-1028.

6. FuH, JE Darroch, T Hass, Ranjit N. Contraceptive failure rates: new estimates from the 1995 National survey of family growth. Fam plan perspect 1999;31: 56-63.

7. U S approved prescribing information for DMPA-contraceptive injection, Pharmacia \& UpjohnCo10-7-2002.

8. H. H. Sangi, A poindexter, L. Bateman, JR Ditmore. Experiences of injectable contraceptive users in an urban setting. Obst gynae1996;88: 227-233.

9. P. C. Schwallie, JR Assenzo. Contraceptive use- efficacy study utilizing medroxyprogesterone acetate administered as an im injection once every 90 days

10. C. Paul, DC S Skegg, S Williams. DMPA, patters of use and reasons for discontinuation.contraception1997;56: 209-214. 
11. M. Kaunitz. Injectable contraception. New and existing options. Obstet gynae Clin North America 2000;27: 741-780.

12. Cromer BA; Smith RD; Blair JM; Dwyer $\mathrm{J}$; Brown RT. Prospective studies of adolescents who choose among levonorgestrel implant (Norplant) medroxyprogesterone acetate (DepoProvera), or the combined oral contraceptive pill as contraception. Pediatrics 1994; 94(5):687-94.
13. $A B$ Berenson, M Rahman. Changes in weight, total fat, percent body fat, and central-to-peripheral fat ratio associated with injectable and oral contraceptive use. American journal of obstetrics and gynaecology. 2009; 200:329.e1-329.e8.

14. Annual Report, Department of health services 2070/71. Family Planning;

\section{1:56-57}

